\title{
Physical Literacy: Importance, Assessment and Future Directions
}

\author{
Susan Giblin • Dave Collins $\cdot$ Chris Button
}

Published online: 5 June 2014

(c) Springer International Publishing Switzerland 2014

\begin{abstract}
Physical literacy (PL) has become a major focus of physical education, physical activity and sports promotion worldwide. PL is a multifaceted conceptualisation of the skills required to fully realise potentials through embodied experience. Substantial financial investments in PL education by governments are underpinned by a wide range of anticipated benefits, including expectations of significant future savings to healthcare, improved physical and psychological well-being of the population, increased work-force productivity and raised levels of expertise in sport and exercise participation. However, disappointingly, scientific evidence showing the efficacy of PL interventions to successfully meet such high expectation is limited. We suggest that contradictions in research findings are due largely to limitations in movement assessment batteries and consequent discrepancies between measurements used to assess the immediate outcomes of PL programmes. Notably, there is no robust empirical tool for evidencing skill learning in the physical movement component of PL, education and this presents a serious limitation to the design of, and claims that can be made for, such
\end{abstract}

\author{
S. Giblin $(\bowtie) \cdot$ D. Collins \\ Institute of Coaching and Performance, University of Central \\ Lancashire, Lancashire, UK \\ e-mail: SGiblin@uclan.ac.uk \\ D. Collins \\ e-mail: DJCollins@uclan.ac.uk \\ D. Collins \\ Grey Matters Performance Ltd., London, UK \\ C. Button \\ School of Physical Education, Sport and Exercise Sciences, \\ University of Otago, Dunedin, New Zealand \\ e-mail: chris.button@otago.ac.nz
}

interventions. Considering the parameters of proficient PL skills and the limitations of current evaluation instruments, possible future directions for developing empirical measures of PL movement skills are presented.

\section{Introduction}

Physical literacy (PL) is a multifaceted conceptualisation of the skills required to fully realise potentials through embodied experience [1]. The concept originates from existential and phenomenological philosophies and considers PL as a crucial component of human existence; a construct that enables individuals to lead a fulfilling life through enriching embodied experiences [1]. Reflecting this contention, the UK, Canada, Australia and New Zealand have recently pioneered large-scale initiatives in education, community and public health settings to promote participation and performance in physical activities (PAs) through PL. For example, during 2013, the Australian Government invested \$200 million Australian dollars (\$A) to develop and implement programmes that promote PA [2]. Future savings for healthcare resulting from improving the population's PA in Australia were estimated to equate to $\$ \mathrm{~A} 13.8$ billion [2]. Therefore, the considerable expense of implementing PA programmes seems justified when the potential return on investment is considered.

Given the perceived importance of PL for improving PA engagement, it is unfortunate that current models used to operationalise this important concept and dictate the structure of PL programmes currently lack an accepted governing standard and vary in interpretation across the globe. Without comparative data to generate evidence for best-practice in developing PL skills, policies can only offer vague guidelines [3]. If PL is as important as claimed 
Table 1 Programmes promoting life-long physical activity

\begin{tabular}{|c|c|c|c|c|}
\hline Intervention & Objective & Setting & Assessment & Assessment limitations \\
\hline CS4L & $\begin{array}{l}\text { Develop PL through sport } \\
\text { and athleticism based on } \\
\text { stages of long-term athlete } \\
\text { development model }\end{array}$ & $\begin{array}{l}\text { Sports clubs } \\
\text { and } \\
\text { community }\end{array}$ & PLAY & $\begin{array}{l}\text { Time/resource-intensive instruction } \\
\text { and demonstration-based movement } \\
\text { assessment }\end{array}$ \\
\hline $\begin{array}{l}\text { Skills } 4 \\
\text { sport } \\
\text { (Northern } \\
\text { Ireland) }\end{array}$ & $\begin{array}{l}\text { Learning key movement } \\
\text { skills leading to } \\
\text { development of sport- } \\
\text { specific skills }\end{array}$ & $\begin{array}{l}\text { Sports club } \\
\text { and } \\
\text { community }\end{array}$ & MAND & $\begin{array}{l}\text { MAND is not suitable for assessing } \\
\text { motor skill longitudinally due to sex, } \\
\text { age and cultural factors mediating the } \\
\text { validity of psychometric properties }\end{array}$ \\
\hline $\begin{array}{r}\text { Start to } \\
\text { move } \\
\text { (UK) }\end{array}$ & $\begin{array}{l}\text { Primary school-based } \\
\text { interventions for training } \\
\text { teachers/coaches to deliver } \\
\text { PL education }\end{array}$ & Schools & $\begin{array}{l}\text { Provides guidelines and training to } \\
\text { teachers and coaches to assess } \\
\text { movement skills based on fundamental } \\
\text { movements }\end{array}$ & $\begin{array}{l}\text { Measures fundamental movements } \\
\text { separately. Instruction- and } \\
\text { demonstration-based movement } \\
\text { assessment }\end{array}$ \\
\hline $\begin{array}{l}\text { Basic } \\
\text { moves } \\
\text { (Scotland) }\end{array}$ & $\begin{array}{l}\text { Basic/fundamental } \\
\text { movement development }\end{array}$ & $\begin{array}{l}\text { Sports club } \\
\text { and } \\
\text { community }\end{array}$ & TGMD & $\begin{array}{l}\text { Summative score provided for overall } \\
\text { skill level based on a dichotomous } \\
\text { 'successful' or 'unsuccessful' rating } \\
\text { of movement skills tested separately }\end{array}$ \\
\hline $\begin{array}{l}\text { Kiwi sport } \\
\text { (New } \\
\text { Zealand) }\end{array}$ & $\begin{array}{l}\text { To develop fundamental } \\
\text { movement skills and } \\
\text { progress to educating } \\
\text { modified sports-specific } \\
\text { skills }\end{array}$ & Sports club & $\begin{array}{l}\text { Non-standardised ('invented') games } \\
\text { used to test fundamental and combined } \\
\text { motor skill level marked on rubric } \\
\text { form for upper/lower/body skills }\end{array}$ & $\begin{array}{l}\text { Non-comparative data due to lack of } \\
\text { standardised assessment }\end{array}$ \\
\hline $\begin{array}{l}\text { Nike } \\
\text { designed } \\
\text { to move } \\
\text { (USA) }\end{array}$ & $\begin{array}{l}\text { Universal programme to } \\
\text { promote fundamental } \\
\text { movement skills }\end{array}$ & $\begin{array}{l}\text { Schools, } \\
\text { sports club } \\
\text { and } \\
\text { community }\end{array}$ & $\begin{array}{l}\text { Provides a database for club, } \\
\text { community, education systems to } \\
\text { report effectiveness }\end{array}$ & $\begin{array}{l}\text { No standardised method of assessing } \\
\text { skill learning. Provides limited } \\
\text { comparative data }\end{array}$ \\
\hline
\end{tabular}

CS4L Canada Sports 4 Life, MAND McCarron Assessment of Neuromuscular Development, PL physical literacy, PLAY Physical Literacy Assessment for Youth, TGMD Test of Gross Motor Development

[1], then a robust empirical evidence base would seem long overdue. Accordingly, we present a critical consideration of the evaluation of PL, in order to examine options for enhancing the evidence base. To source relevant available literature, electronic databases (ScienceDirect, PsycINFO, Wiley) were searched using the terms 'motor-skill' OR 'movement skills' AND 'physical literacy' OR 'physical education' AND 'assessment' OR 'evaluation'. The date range set for the search was January 1989-September 2013. Abstracts were examined, and relevant articles were further examined if they included a measure of physical skill competence used to test physical ability in children.

\section{Physical Literacy (PL) as the Primary Focus for Physical Education}

Physical education is an almost ubiquitous resource provided by schools to teach physical skills and promote PA. Research investigating the influence of skill development on parameters of PA later in life shows contrasting results [4-8]. One reason for the contradicting research findings appears to be the wide variety of assessment tools employed to test the physical skill component of programmes designed to promote life-long PA. In the absence of a 'gold standard', the variation in methods for assessing interventions has arguably impeded the development of further longitudinal studies and led to interventions that encompass a broad variety of definitions and objectives [48]. These issues are summarised through exemplar different PA programmes across the world in Table 1.

Whitehead's [1,9] model describes the behavioural, psychological and physical components that encompass PL. Psychological correlates include perceived competence, enjoyment and belief that engaging in physical pursuits is worthwhile [1]. Behavioural characteristics, such as goal setting, imagery and reflection, appear to play a crucial role in the realisation of potential by enabling individuals to invest the requisite time to practice, avoid distractions and stay committed to pursuing personal excellence in PAs throughout life. Although distinct, the components of PL are inter-linked, i.e. physical skills are required to utilise psychological and behavioural concomitants of PL. However, notably, while the psychological and behavioural components have achieved some consistency of understanding, the physical component remains obfuscated by the variety of measurements used in its operationalisation. Explicit focus on physicality is a feature of Whitehead's [1] original ideas, which categorised PL movement skills into three movement capacities (i.e. 
Table 2 Summary of physical movement capacities [39]

\begin{tabular}{lll}
\hline Simple movement capacities & Combined movement capacities & Complex movement capacities \\
\hline Core stability & Poise (both balance and core stability) & Bilateral coordination \\
Balance & Fluency (coordination, balance and proprioception) & Inter-limb coordination \\
Coordination & Precision (accurate placement of the body and core stability) & Hand-eye coordination \\
Flexibility speed variation & Dexterity (coordination, accurate placement and flexibility) & Control of acceleration/deceleration \\
Control proprioception power & Equilibrium (balance, core stability and movement control) & Turning and twisting Rhythmic movement \\
\hline
\end{tabular}

fundamental, combined and complex). However, the exact balance of physical capacities required to attain proficient PL has yet to be clearly expressed. A summary of generally accepted physical movement capacities is shown in Table 2.

Our point is that, in the absence of evidence-based guidance, programmes to provide PL education may focus (we suggest erroneously) on developing simple movements. At first sight, the attention to simple movement capacities seems sensible. Well founded generic athletic abilities (e.g. balance, locomotion, strength) underpin almost all physical pursuits [10-12]. Developing fundamental movement competence is imperative to perceived competence and confidence that is associated with improving and increasing PA and correlates with physical fitness levels in adolescence and adulthood [13]. Whilst basic movement skills are undoubtedly imperative, their role in PL education requires consideration if the objective is to promote higher-order motoric competence. For example, neither balance (static, reactive or proactive) nor strength shows statistically significant correlations to functional performance tests (e.g. timed 'up and go') [14]. Combining basic movements is essential to engage in advanced physical experiences in a variety of domains. For example, Seifert et al. [15] show that adaptability and variation in combinations of motor patterns enable individuals to display mastery in previously learned movements and to gain new movement knowledge from executing motor skills in a variety of novel combinations. Our point here is that the current popular emphasis on fundamental skills may not be appropriate for realisation of the benefits claimed for PL. As such, physical exercise (PE) programmes, guided ideally by evidence, should be ensuring the development of more sophisticated elements of motor coordination, as shown in the right-hand column of Table 2. Of course, the veracity of such suggestions awaits the development of more accurate measures of PL.

\section{Evaluating PL}

In addition to the lack of comparative data due to nonstandardised testing (Table 1), skill learning 'confounds' the external validity of action-based longitudinal PL research to date [16]. In the context of PL, assessment should test self-regulated execution of gross motor coordination in a range of tasks to measure individuals' strengths/weaknesses, including specific evidence of learning and skill progression to track development over time. However, movement assessment batteries most commonly used in research were designed to test for motor development impairment [17, 18]. Assessment batteries use either 'product-focused' or 'process-focused' methods to examine movement skills. Product-focused measures offer objective information indicating the time taken or the number of trials an individual needs to successfully complete a predetermined task (such as the Movement Assessment Battery for Children [M-ABC]). Such tests constrain movement to set time, space and procedural parameters. Product-focussed assessments have been criticised for lacking the sensitivity required to detect individual differences in movement abilities considering the idiosyncratic nature of optimal motor pattern execution [19].

Process-orientated assessments examine movement quality and provide valuable movement data; however, reliability confounds are present due to the influence of assessor experience and subjectivity on test scores [18]. Also, environmental constraints influence testing procedures (equipment used) and the performance of the individuals being assessed (e.g. assessor relations, noise, audience observation, etc.). Despite their clinical origin, these movement analysis procedures are increasingly adopted in education and sports settings as a general assessment of motor ability by coaches, teachers and researchers.

Furthermore, the validity, reliability and sensitivity of applying battery assessments to test movement are limited without considering the contextual inferences of the test $[16,20]$. In the context of an appropriate movement-based PL assessment, the current batteries have a number of limitations. For example, the Test of Gross Motor Development 2nd edition (TGMD-2) provides a summative score for the performance of separate motor skills: the individual receives a score of 1 if the skill is completed and 0 if not. This seems a rather 'black and white' but contrastingly 
subjective evaluation of a surely continuous variable. The TGMD-2 also constricts movement skills to a specific context, i.e., a skill level deemed fundamental for normal motor development. Skills considered fundamental to PL development should surely include more complexity and sophistication.

The context of movement ability remains constrained by set tasks and performance criteria throughout a number of battery tests. The M-ABC focuses on measuring balance, manual dexterity and ball skills using quantitative outcomes of trials completed within set boundaries. Take, for example, the object-manipulation task, which provides information about an individuals' ability to throw a tennis ball in a certain predefined way (overhand). However, notably, it does not depict a generalisable motor ability (i.e. the motoric competence required to adapt movement skills and throw an oval-shaped ball underhand). As highlighted earlier, these tests were originally intended for use in clinical settings as a discriminative measure to characterize motor deficiency [21].

A number of pragmatic issues are also associated with the various tests. For example, the time requirements to perform individual assessment compromises practical application in school settings. The M-ABC takes 20-25 min to test per individual and requires administration in a separate room [17]. Additionally, norm-based movement tests lack the flexibility required to monitor individual-specific progress in motor skill learning that varies as a function of age, gender and cultural factors [16, 20, 22, 23]. As a cross-cultural example, the McCarron Assessment of Neuromuscular Development is a normbased assessment originating from the USA that has limited validity when used to test movement ability of Australian cohorts [16].

Movement assessments also predominantly involve skill-instruction guidelines or a demonstration by the tester prior to assessment [22]. As such, these tools provide results that may be more indicative of a demonstrator's expertise and/or a child's mimicry skills than the individual's knowledge, level and understanding of movement skills. This is not to say that reproducing a demonstrated movement is not an important component of PL; however, it is also not representative of an individual's ability to interpret task demands and select appropriate movements from their repertoire of motor competence in response.

The validity of assessments is further contested by a lack of consideration for the relative importance of factors contributing to physical proficiency. Reflecting our earlier comments, whilst developing a fundamental base of movement skills is essential, proficiency in combined and complex movement capacities is surely more imperative to becoming physically literate. Attaining sufficient competence in basic movements provides individuals with the motivation and perceived ability to participate and progress in PA [13, 24]. However, some movement skills impact on future progression and participation in $\mathrm{PA}$ to a greater extent than others. Gross motor coordination accounted for $40 \%$ of the variance detected on discriminant tests used on children with and without motor impairment [18], whereas individual scores for flexibility, fine motor skills or locomotion did not show any significant relation to future levels of PA [24] or overall scores of motor ability [18]. However, motor skill assessments often aggregate components together in an unweighted total; i.e. each factor is treated as important as the next, even though some components are measured more often and, therefore, make a bigger contribution. Additionally, motor skill assessments typically require individual administration, demonstration and equipment, making them challenging to implement in practical settings. As an example, the Bruininks-Oseretsky test of motor proficiency, second edition (BOT-2) [21] is an individually administered, norm-based measure of fine and gross motor skills used to assess skill development. Finally, but no less important, all of the evaluations we have reviewed fail to test an individuals' ability to evaluate a task, then combine and adapt motor skills to novel environments, clearly a major expected feature of those presumed to be high in PL [1].

\section{Implications of Limited PL Evaluation}

The empirical evidence base supporting PL depicts contradictory findings that, we suggest, reflect either a flawed construct of PL or, more likely, inappropriate use or interpretation of movement data. If the primary objective of PL education is life-long PA (facilitated by physical proficiency), not immediate fitness gains, the outcomes of PL development initiatives should reflect these aims. Clearly, the behavioural, psychological and physical components of PL are (theoretically and practically) distinct but interlinking constructs. Integrating evaluation of the constructs should provide a more accurate assessment of an individual's PL ability. Therefore, as iterated in our earlier arguments, an appropriate physical skill evaluation is required to meet the objective of integrated monitoring in all parameters of PL education.

Researchers have addressed the need for standardisation and clarification between measuring tools that report the same objective but which, confusingly, provide different information [25]. Process-focussed qualitative movement tests that provide standard definitions and descriptions to guide the tester and reduce subjective bias have also been developed [22, 26]. However, important movement capacities have often been omitted from qualitative measurements due to difficulties in observing certain 
characteristics (e.g. movement fluency). A possible caveat of including complex movement skills in evaluations is increased measurement error that reduces test reliability. Careful refinement will be required to produce reliable assessments of complex movement skills. Nonetheless, we suggest that such efforts must be made if we are to generate a valid and meaningful tool.

In short, research is required to establish appropriate procedures for testing movement ability that provide empirical monitoring on micro (individual) or macro (intervention) levels. This, in turn, should generate valid, reliable measures that reduce demands on resources without compromising the quality of data measured.

\section{Future Directions for Enhancing PL Evaluation: The Potential of "Exer-Gaming" Techniques}

The movement battery assessments used at present do not coherently link test outcomes to the objectives of PL education as conceptualised by Whitehead [1, 9]. Specifically, the movement capacities that demonstrate deep and meaningful learning of physical skills are neglected. Some assessment batteries used facilitate assessor ease but provide limited information that lacks objectivity and largely focuses on basic movement abilities.

As a new direction, and in order to address these various issues, we suggest that movement assessments that use commercially popular motion capture systems (e.g., Microsoft ${ }^{\circledR}$ Kinect, Nintendo Wii, etc.) could provide a potential solution. Exer-gaming is a portmanteau of exercise and gaming used to describe video games that require physical body movement to engage in gaming activity. The exer-gaming phenomenon has become a recent focus of research in physical health, leisure [8, 27-30] and clinical [31] contexts, albeit with mixed results. However, these issues notwithstanding, the exer-gaming technological platform may provide objective, accessible and sensitive methods of monitoring learning in the context of becoming physically literate, even if their potential as exercise stimuli is more limited. Furthermore, adopting similar methods to assess movement in PE could potentially provide an ecologically valid and child-friendly/accepted measure to test the effectiveness of PL programmes. The rapidly increasing popularity of exer-gaming across the globe could provide a means of assessing and tracking motor learning that can be used comparatively across nations to establish an evidence-based protocol for designing and delivering quality PL education.

As stated, exer-gaming interventions have been tried, although with mixed results. The Centre for Exer-gaming Research Canada (CERC) and Canada Sports 4 Life (CS4L) have recognised the potential of exer-gaming technology to provide enhanced education, compliance, motivation and commitment to $\mathrm{PE}$ compared with traditional PE models [29, 32]. However, the impact of exergames on PA levels and fitness vary depending on game design and PA parameters measured. For example, studies found that exer-games designed to improve movement skills (e.g. balance), or using upper-limb movement only, induced light-moderate PA levels [29, 33]. In contrast, exer-games designed to engage whole-body movements (Dance, Dance Revolution) resulted in moderate-vigorous activity levels, energy expenditure and heart rate increases equal to traditional PA engagement (running) [33]. Exergames also improved functional fitness in overweight children [33], although increased traditional PA and exergaming PA correlated with increased sedentary behaviour and no significant differences in overall activity levels compared with control groups [33].

In addition to the physical component, exer-gaming impacts the psychological and behavioural aspects of PL: 'Online' visual feedback provides the opportunity for intrinsic task correction to facilitate motor skill learning [35]. Motivation and enjoyment of PA participation increased through exer-gaming interventions compared with traditional PA, particularly in 'at risk' populations [30, 33].

Given these mixed outcomes, the effectiveness of exergames as a means of increasing PA clearly requires further research. However, as stated above, the use of exer-game technology could provide an appropriate method for assessing movement competence. Low-cost motion capture devices used in PE could enhance the quality of movement testing procedures, provide individualised and detailed feedback and allow longitudinal data gathering to monitor motor skill development. Exer-games currently used in education evaluate markers of physical fitness (body mass index [BMI]) or simple movement capacities (balance, postural stability) [35]. Exer-game technology provides scope for testing (and teaching) all PL parameters (behavioural, psychological and physical) across a range of levels (fundamental-advanced). Clearly, further longitudinal research is required to establish the optimal design of exer-games used to educate and evaluate PL skills. Some examples of tasks that we are currently developing via the exer-gaming platform to enhance the quality of PL testing are listed in Table 3 [33-35].

We should acknowledge that numerous barriers are still to be negotiated before exer-gaming can be considered as a potential alternative to movement assessment batteries to monitor movement competency on a large scale. As we have discussed, the physical capacities that are fundamental to PL need to be verified and weighted appropriately in accordance with the motor learning literature. In practical terms, the accuracy and sensitivity of commercial 
Table 3 Examples of possible physical literacy movement assessment tasks

\begin{tabular}{|c|c|c|c|}
\hline Coordination characteristic & $\begin{array}{l}\text { Physical literacy skills } \\
\text { involved }\end{array}$ & Description & Evaluation of skill learning \\
\hline $\begin{array}{l}\text { Interceptive timing, e.g. } \\
\text { basketball, tennis, } \\
\text { baseball, cricket }\end{array}$ & $\begin{array}{l}\text { Visual perception } \\
\text { timing } \\
\text { Control unimanual and } \\
\text { bimanual coordination } \\
\text { Limb dominance } \\
\text { Ballistic power }\end{array}$ & $\begin{array}{l}\text { A bouncing ball is projected across the } \\
\text { screen in front of the participant. The } \\
\text { participant has to 'strike' the virtual ball } \\
\text { inside a highlighted target zone on the } \\
\text { screen using their hand/s. Each hand is } \\
\text { tested separately and two hands together } \\
\text { to measure bimanual co-ordination and } \\
\text { hand dominance. Spatio-temporal } \\
\text { coordination in interceptive actions } \\
\text { between hand and ball are measured }\end{array}$ & $\begin{array}{l}\text { Varying level of difficulty in ball speed, } \\
\text { size of target zone, predictability of } \\
\text { bounce. Motion sensors used to detect } \\
\text { the movements of the punching limb/s. } \\
\text { Measuring coupling of hand motion to } \\
\text { lateral ball position, occurrence of peak } \\
\text { hand acceleration relative to target zone, } \\
\text { resultant velocity/direction of ball } \\
\text { following impact, etc. }\end{array}$ \\
\hline $\begin{array}{l}\text { Object manipulation, e.g. } \\
\text { archery }\end{array}$ & $\begin{array}{l}\text { Visual-perception hand- } \\
\text { eye coordination } \\
\text { Control } \\
\text { Precision } \\
\text { Timing } \\
\text { Fine motor skill }\end{array}$ & $\begin{array}{l}\text { Pick up different sized balls and put them } \\
\text { in a container using a virtual crane } \\
\text { controlled by the participants' actual } \\
\text { hand movements testing the spatio- } \\
\text { temporal accuracy of the movement of } \\
\text { the crane to the balls, and the co- } \\
\text { ordination between opening and closing } \\
\text { of the virtual 'claw' [35] }\end{array}$ & $\begin{array}{l}\text { Variations in ball size. Timing and } \\
\text { accuracy of trapping ball. Timing and } \\
\text { accuracy of ball placement }\end{array}$ \\
\hline $\begin{array}{l}\text { Locomotion and agility, } \\
\text { e.g. gymnastics, athletics }\end{array}$ & $\begin{array}{l}\text { Visual-perception } \\
\text { Kinesthetic awareness } \\
\text { Postural control } \\
\text { Gross motor adaptation }\end{array}$ & $\begin{array}{l}\text { Task requires quiet standing with feet } \\
\text { together; standing shifting weight from } \\
\text { one foot to the other as if making a step; } \\
\text { normal walking; and walking with } \\
\text { changes in direction, level change } \\
\text { (squat). Motion analysis sensors monitor } \\
\text { movements of the head, top and bottom } \\
\text { of spine, hips, knees, ankles and feet }\end{array}$ & $\begin{array}{l}\text { Increased stability of centre of mass } \\
\text { within base of support. Decreased time } \\
\text { to achieve centre of mass stability } \\
\text { changing base of support }\end{array}$ \\
\hline $\begin{array}{l}\text { Rhythm and sequencing, } \\
\text { e.g. rugby, soccer, } \\
\text { hockey, dance }\end{array}$ & $\begin{array}{l}\text { Perception of rhythm } \\
\text { Timing } \\
\text { Intra-limb coordination } \\
\text { Stability of bimanual } \\
\text { coordination }\end{array}$ & $\begin{array}{l}\text { Learn a number of simple to complex } \\
\text { rhythms/patterns and reproduce them } \\
\text { with a bimanual tapping movement [36] }\end{array}$ & $\begin{array}{l}\text { Accuracy of pattern repetition; accuracy } \\
\text { of recall with decreased feedback/ } \\
\text { auditory occlusion; time/number of } \\
\text { trials taken to achieve task }\end{array}$ \\
\hline $\begin{array}{l}\text { Spatial awareness and } \\
\text { balance, e.g. ice-skating, } \\
\text { skiing, diving, } \\
\text { gymnastics, track and } \\
\text { field events }\end{array}$ & $\begin{array}{l}\text { Visual perception } \\
\text { Kinesthetic integration } \\
\text { Imagery } \\
\text { Planning, postural } \\
\text { control, stability }\end{array}$ & $\begin{array}{l}\text { Adopt and hold different spatial } \\
\text { configurations of their body and limbs to } \\
\text { suit expanding apertures on the screen. } \\
\text { Hence the task is somewhat akin to a } \\
\text { version of 'Human Tetris'. Sensory } \\
\text { organisation and postural stability will be } \\
\text { assessed via composite performance } \\
\text { measures [36] }\end{array}$ & $\begin{array}{l}\text { Time taken to achieve shape. Accuracy of } \\
\text { movement. Increased speed of transition } \\
\text { between shapes. Increased complexity } \\
\text { of shapes }\end{array}$ \\
\hline
\end{tabular}

exer-gaming equipment requires rigorous testing against accepted motion analysis systems. Furthermore, the limited accessibility and acceptance of such technologies in certain countries and communities also needs to be considered as a socio-cultural constraint. Finally, one may also raise ethical concerns about the promotion of exer-gaming as the 'saviour' in the face of decreasing levels of PA and increasing childhood obesity [37]. We acknowledge that the immediacy of the obesity epidemic necessitates PE that increases moderate to vigorous PA levels and physical fitness presently. We suggest that appropriately designed PE could, indeed, should combine moderate to vigorous PA with lifelong physical skill learning. Alongside consideration of these barriers, the 'potential versus the actual' benefits of exer-gaming need to be verified [38] and it is hoped this article may help to provoke such research.

\section{Conclusion}

PL is a pertinent concept in pedagogical education terms and interlinks physical, psychological and behavioural skill learning. Adequate physical movement assessments would provide a more robust evidence base to support the PL construct. Combining the advances in understanding in neuroscience underpinning physical skill learning and 
expertise with exer-gaming technology could provide accessible, appropriate methods for both teaching and monitoring of PL education.

Some progress is evident. The current standardisation of monitoring methods [2] shows progression in optimising evidence-based PL education. However, further development within PL education using exer-gaming programmes could improve the measurement of movement skills that reflect skill learning in all PL parameters and provide valid and comparable empirical data to assess effectiveness in PL education (e.g. Table 3). Further research is required to examine the effectiveness of exer-gaming applications for evaluating physical movement skills that reflect proficient PL. Such empirical evidence is required to test the validity of both PL and exer-gaming for providing optimal physical education.

Acknowledgments No sources of funding were used to assist in the preparation of this article. The authors have no potential conflicts of interest that are directly relevant to the content of this article.

\section{References}

1. Whitehead M. Physical literacy: throughout the lifecourse. 1st ed. London: Routledge; 2010. p. 5-13.

2. Keegan RJ, Keegan SL, Daley S, et al. University of Canberra. Centre for Excellence in Physical Literacy and Active Youth (CEPLAY). Getting Australia moving: establishing a physically literate and active nation (game plan). University of Canberra; 2013.

3. Bellew B, Bauman A, Brown W. Evidence-based policy and practice of physical activity in Australia: awareness and attitudes of attendees at a national physical activity conference (the PAPPA study). Health Promot J Aust. 2010;21:222-8.

4. Barnett LM, van Beurden E, Morgan PJ, et al. Childhood motor skill proficiency as a predictor of adolescent physical activity. J Adolesc Health. 2009;44:252-9.

5. Liu W, Chepyator-Thomson J. Field dependence-independence and physical activity engagement among middle school students. Phys Educ Sport Pedagog. 2009;14:125-36.

6. Masci I, Vannozzi G, Bergamini E, et al. Assessing locomotor skills development in childhood using wearable inertial sensor devices: the running paradigm. Gait Posture. 2013;37:570-4.

7. Mitchell B, McLennan S, Latimer K, et al. Improvement of fundamental movement skills through support and mentorship of class room teachers. Obes Res Clin Pract. 2013;7:230-4.

8. Sheehan DP, Katz L. The pursuit of physical literacy: can exergaming develop fundamental movement skills like balance? Can J Diabetes. 2011;35:174.

9. Whitehead M. Physical literacy: philosophical considerations in relation to developing a sense of self, universality and propositional knowledge. Sport Ethics Philos. 2007;1:281-98.

10. Goodway JD, Branta CF. Influence of a motor skill intervention on fundamental motor skill development of disadvantaged preschool children. Res Quart Exerc Sport. 2003;74:36-46.

11. Lubans DR, Morgan PJ, Cliff DP, et al. Fundamental movement skills in children and adolescents: review of associated health benefits. Sports Med. 2010;40:1019-35.

12. Lawford HL, Ramey HL, Rose-Krasnor L, et al. Predictors of adolescent successful development after an exchange: the importance of activity qualities and youth input. J Adolesc. 2012;35:1381-91.

13. Stodden DF, Goodway JD, Langendorfer SJ, et al. A developmental perspective on the role of motor skill competence in physical activity: an emergent relationship. Quest. 2008;2: 290-306.

14. Muehlbauer T, Besemer C, Wehrle A, et al. Relationship between strength, balance and mobility in children aged 7-10 years. Gait Posture. 2013;37:108-12.

15. Seifert L, Wattebled L, L'Hermette M, et al. Skill transfer, affordances and dexterity in different climbing environments. Human Mov Sci. 2013;32(6):1339-52.

16. Hands B, Larkin D, Rose E. The psychometric properties of the McCarron assessment of neuromuscular development as a longitudinal measure with Australian youth. Human Mov Sci. 2013;32:485-97.

17. Cools W, De Martelaer K, Vandaele B, et al. Assessment of movement skill performance in preschool children: convergent validity between MOT 4-6 and M-ABC. J Sports Sci Med. 2010;9:597-604.

18. Schoemaker MM, Niemeijer AS, Flapper BC, et al. Validity and reliability of the movement assessment battery for children-2 checklist for children with and without motor impairments. Dev Med Child Neurol. 2012;54:368-75.

19. Brisson TA, Alain C. Should common optimal movement patterns be identified as the criterion to be achieved? J Mot Behav. 1996;28:211-23.

20. Larsson H, Quennerstedt M. Understanding movement: a sociocultural approach to exploring moving humans. Quest. 2012;64:283-98.

21. Deitz JC, Kartin D, Kopp K. Review of the Bruininks-Oseretsky test of motor proficiency (BOT-2). Phys Occup Ther Pediatr. 2007;27:87-102.

22. Janssen AJWM, Diekema ETW, van Dolder R, et al. Development of a movement quality measurement tool for children. Phys Ther. 2012;92:574-94.

23. Venetsanou F, Kambas A, Aggeloussis N, et al. Motor assessment of preschool aged children: a preliminary investigation of the validity of the Bruininks-Oseretsky test of motor proficiencyShort form. Human Mov Sci. 2009;28:543-50.

24. Lopes L, Santos R, Pereira B, et al. Associations between sedentary behavior and motor coordination in children. Am J Hum Biol. 2012;24:746-52.

25. Logan SW, Morera M, Daly CM, et al. The comparison of two motor assessments in elementary school children. Br J Sports Med. 2010;44:81-2.

26. Dyson B, Placek JH, Graber KC, et al. Development of PE metrics elementary assessments for national physical education standard 1 measurement. Phys Ed Exerc Sci. 2011;15:100-18.

27. Best JR. Exergaming immediately enhances children's executive function. Dev Psychol. 2012;48:1501-10.

28. Best JR. Exergaming in youth. J Psychol. 2013;221:72-8.

29. Sheehan DP, Katz L. The effects of a daily, 6-week exergaming curriculum on balance in fourth grade children. J Sport Health Sci. 2013;2:131-7.

30. Sun H. Impact of exergames on physical activity and motivation in elementary school students: a follow-up study. J Sport Health Sci. 2013;2:138-45.

31. Klingberg T, Fernell E, Olesen PJ, et al. Computerized training of working memory in children with ADHD-a randomized, controlled trial. J Am Acad Child Adolesc Psych. 2005;44:177-86.

32. Sheehan D, Katz L. Using interactive fitness and exergames to develop physical literacy. PHE J. 2010;76:12-9.

33. Biddiss E, Irwin JJ. Active video games to promote physical activity in children and youth: a systematic review. Arch Paediatr Adolesc Med. 2010;164:664-72. 
34. Jeannerod M, Marteniuk RG. Functional characteristics of prehension: from data to artificial neural networks. In: Proteau L, Elliott D, editors. Vision and motor control. Amsterdam: Elsevier Science; 1992.

35. Olivier I, Hay L, Bard C, et al. Age-related differences in the reaching and grasping coordination in children: unimanual and bimanual tasks. Exper Brain Res. 2007;179:17-27.

36. Fong S, Tsang W, Ng G. Altered postural control strategies and sensory organization in children with developmental coordination disorder. Human Mov Sci. 2012;31(5):1317-27.
37. Vander Schee CJ, Boyles D. 'Exergaming,' corporate interests and the crisis discourse of childhood obesity. Sport Educ Soc. 2010;15:169-85.

38. Sallis JF. Potential vs actual benefits of exergames. Arch Pediatr Adolesc Med. 2011;165:667-9.

39. Whitehead M, editor. Physical literacy: throughout the lifecourse. London: Routledge; 2010. 